\title{
A systematic review and meta-analysis on the prevalence of stigma in infectious diseases, including COVID-19: a call to action
}

\author{
Kai Yuan (D) ${ }^{1,10}$, Xiao-Lin Huang ${ }^{1,2,10}$, Wei Yan $\mathbb{D}^{1,10}$, Yu-Xin Zhang ${ }^{1,3}$, Yi-Miao Gong ${ }^{1,3}$, Si-Zhen Su ${ }^{1}$, Yue-Tong Huang ${ }^{1}$, Yi Zhong ${ }^{1,3}$, \\ Yi-Jie Wang ${ }^{1,3}$, Ze Yuan ${ }^{2}$, Shan-Shan Tian ${ }^{1}$, Yong-Bo Zheng ${ }^{1,3}$, Teng-Teng Fan ${ }^{1}$, Ying-Jian Zhang ${ }^{1}$, Shi-Qiu Meng ${ }^{4}$, Yan-Kun Sun ${ }^{1}$,

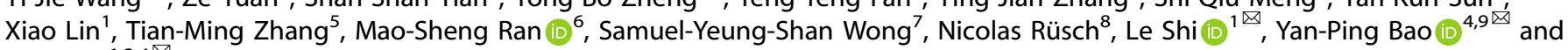 \\ Lin Lu (iD ${ }^{1,3,4 \bowtie}$
}

(c) The Author(s), under exclusive licence to Springer Nature Limited 2021

Infectious diseases, including COVID-19, are crucial public health issues and may lead to considerable fear among the general public and stigmatization of, and discrimination against, specific populations. This meta-analysis aimed to estimate the pooled prevalence of stigma in infectious disease epidemics. We systematically searched PubMed, PsycINFO, Embase, MEDLINE, Web of Science, and Cochrane databases since inception to June 08,2021, and reported the prevalence of stigma towards people with infectious diseases including SARS, H1N1, MERS, Zika, Ebola, and COVID-19. A total of 50 eligible articles were included that contributed 51 estimates of prevalence in 92722 participants. The overall pooled prevalence of stigma across all populations was $34 \%$ [95\% $\mathrm{Cl}$ : $28-40 \%]$, including enacted stigma (36\% [95\% Cl: $28-44 \%]$ ) and perceived stigma (31\% [95\% Cl: $22-40 \%]$ ). The prevalence of stigma in patients, community population, and health care workers, was 38\% [95\% Cl: $12-65 \%$ ], 36\% [95\% Cl: $28-45 \%$ ], and 30\% [95\% Cl: $20-40 \%$, respectively. The prevalence of stigma in participants from low- and middle-income countries was 37\% [95\% Cl: $29-45 \%]$, which is higher than that from high-income countries (27\% [95\% Cl: $18-36 \%])$ though this difference was not statistically significant. A similar trend of prevalence of stigma was also observed in individuals with lower education (47\% [95\% Cl: 23-71\%]) compared to higher education level (33\% [95\% Cl: $23-4 \%])$. These findings indicate that stigma is a significant public health concern, and effective and comprehensive interventions are needed to counteract the damaging effects of the infodemics during infectious disease epidemics, including COVID-19, and reduce infectious disease-related stigma.

Molecular Psychiatry (2022) 27:19-33; https://doi.org/10.1038/s41380-021-01295-8

\section{INTRODUCTION}

The outbreak of the coronavirus disease 2019 (COVID-19) around the world has brought public attention to infectious disease epidemics again [1]. In fact, infectious diseases have become more frequent and more complex in recent years, with notable examples such as severe acute respiratory syndrome (SARS), influenza A subtype H5N1, Zika, Ebola, and Middle East respiratory syndrome coronavirus (MERS-CoV) [2], which pose a health threat to the general public and are issues of concern for public health professionals in terms of preventing their spread, promoting public awareness, and educating the public about the diseases [3-5].

In view of the possibility of the rapid spread of infectious diseases, infodemics (the rapid and far-reaching dissemination of information of questionable quality) during epidemics and subsequent protracted physical and psychological morbidity and mortality, epidemic-related stigma emerges consequently [6-9]. Stigma is described as an attribute that is deeply discreditable or undesirable [10] and is further conceptualized as a social process of labeling, stereotyping, and prejudices that lead to segregation, devaluation, and discrimination [10]. Various layers of stigma are explored, including enacted (experienced) stigma and perceived public (anticipated) stigma. Enacted stigma refers to actual negative actions taken against someone due to their infection status [11]. Perceived public stigma refers to the perception of being stigmatized and the anticipation of being discriminated against [12].

Populations vulnerable to stigma during infectious disease epidemics involve both infected individuals and health care

\footnotetext{
${ }^{1}$ Peking University Sixth Hospital, Peking University Institute of Mental Health, NHC Key Laboratory of Mental Health (Peking University), National Clinical Research Center for Mental Disorders (Peking University Sixth Hospital), Chinese Academy of Medical Sciences Research Unit (No.2018RU006), Peking University, Beijing, China. ${ }^{2}$ Savaid Medical School, University of Chinese Academy of Sciences, Beijing, China. ${ }^{3}$ Peking-Tsinghua Centre for Life Sciences and PKU-IDG/McGovern Institute for Brain Research, Peking University, Beijing, China. ${ }^{4}$ National Institute on Drug Dependence and Beijing Key Laboratory of Drug Dependence, Peking University, Beijing, China. ${ }^{5}$ Department of Social Work, Shanghai University, Shanghai, China. ${ }^{6}$ Department of Social Work and Social Administration, University of Hong Kong, Hong Kong, China. ${ }^{7} J C$ School of Public Health and Primary Care, The Chinese University of Hong Kong, Hong Kong SAR, China. ${ }^{8}$ Department of Psychiatry II, Ulm University and BKH Günzburg, Ulm, Germany. ${ }^{9}$ School of Public Health, Peking University, Beijing, China. ${ }^{10}$ These authors contributed equally: Kai Yuan, Xiao-Lin Huang, Wei Yan. ${ }^{\circledR}$ email: leshi@bjmu.edu.cn; baoyp@bjmu.edu.cn; linlu@bjmu. edu.cn
}

Received: 5 March 2021 Revised: 17 August 2021 Accepted: 8 September 2021

Published online: 27 September 2021 
workers, especially frontline medical staff [9]. Substantial incidents of stigmatization of healthcare workers and patients have come up during the COVID-19 pandemic across the world [13]. Some patients were fearful of being shamed and accused by others [14], which will bring extra psychological burden to patients and can hinder their social adaptation after recovery. As for frontline medical workers, they were at higher risk of being exposed to COVID-19 virus when working in the hospitals or clinics. Stigma from their families and friends might increase their psychological stress and interfere with their normal work [9]. It was even reported that patients recovered from COVID-19 infection and medical workers were denied access to public transportation, assaulted on the street or in the ordinary course of work, and forced to move out of their rented houses $[15,16]$. However, these over-generalized applications of stereotypes should be differentiated from realistic fear caused by epidemics. In this case, negative reactions to involved populations does not necessarily mean stigmatization. Some kind of avoidance or social distancing measures during epidemics (e.g., imposing shelter-inplace orders, restricting dining-in at restaurants, home isolation) are required and have been shown effective in containing the spread of the virus [17].

Stigma and discrimination may cause mental stress, physical harm, and loss of jobs and educational opportunities for involved populations, and further pose a serious threat to the control of epidemics and the recovery and development of the economy and society $[13,18,19]$. Evidence has suggested that stigma contributed to psychological distress and acute and posttraumatic stress (PTSD) of affected patients and healthcare workers during SARS, H1N1, MERS, Ebola, and COVID-19 outbreaks [20-23]. A cross-sectional study also found that higher level of depression and anxiety were significantly associated with the experience of health facility-related stigma among Ebola survivors [24]. Therefore, stigma can be a hindrance for the public to have an accurate understanding of the disease and can act as a barrier for them to adopt health promoting behavior, seek health care and adhere to treatment, which may lead to suboptimal control of epidemics $[25,26]$.

As COVID-19 might be a continuing threat for the human society, stigma related to this pandemic would be a long-term concern for wellbeing, social recovery, and development in a long time [27]. The rapid spread of the pandemic was associated with high levels of fear $[28,29]$. From a public health perspective, fear and its associated stigma constituted the high impact of the pandemic [30]. Stigma is a barrier to help-seeking. That means people may not use services (diagnostics, prevention, and/or treatment) in order to avoid labeling/stigma. Therefore, fear associated with stigma and discrimination has significantly compromised the public health efforts [31, 32]. Identifying the influence of stigma during the pandemic would be helpful not only for the mental health of affected patients, but also for policy making and social support services globally. However, there is a lack of quantitative estimate of stigma profiles and risk factors among affected individuals during infectious disease epidemics. Therefore, this systematic review and meta-analysis aimed to evaluate the prevalence of stigma during infectious disease epidemics, including COVID-19, to raise public health concern and call for actions to promote the development of effective and comprehensive interventions to reduce infectious disease-related stigma.

\section{METHODS}

\section{Search strategy and selection criteria}

We performed a systematic review and meta-analysis in accordance with preferred reporting items for systematic reviews and meta-analyses (PRISMA) guidelines (Table S1) [33]. The protocol was registered in International Prospective Register of Systematic Reviews (PROSPERO
CRD42020206287 at www.crd.york.ac.uk/PROSPERO). We searched the PubMed, PsycINFO, Embase, MEDLINE, Web of Science, and Cochrane databases to identify studies that reported the prevalence of stigma during infectious disease epidemics, including SARS, MERS, H1N1, H5N1, Zika, Yellow fever, Ebola, Viral Haemorrhagic fevers, and COVID-19, since inception to June 8, 2021. However, other infectious diseases like tuberculosis were not included in our study, as we focused on the infectious diseases that cause a sudden increase in the number of infected cases in a short period of time, of which the outbreak has posed serious public health threats and has been associated with stigma and discrimination against related populations. The search terms were shown in the Appendix. The literature search was limited to English. We also checked the reference lists and review articles for additional studies that might meet the inclusion criteria.

Three researchers (Huang XL, Zhang YX, and Huang YT) independently assessed the articles for their eligibility for inclusion. The studies that met the following criteria were included: (1) cross-sectional or cohort studies on the epidemics of infectious diseases including SARS, MERS, H1N1, H5N1, Zika, Yellow fever, Ebola, Viral Haemorrhagic fevers, and COVID-19; (2) defining stigma via self-reported perception or questionnaires; and (3) directly providing prevalence of stigma or sufficient data to calculate the prevalence. Exclusion criteria were as follows: (1) guidelines, book sections, case-reports, commentaries, and conference abstracts; and (2) studies that measured stigma as a numerical variable without cut-off value and the prevalence could not be calculated. If the same population was used in more than one publication, only one publication with the most comprehensive information would be included. The process of identifying eligible studies and the reasons for exclusion are shown in Fig. 1 and eTable 1 in Appendix.

\section{Data extraction}

The data were independently extracted from eligible papers by researchers (Huang $\mathrm{XL}$, Huang $\mathrm{YT}$, Zhong $\mathrm{Y}$, and Wang $\mathrm{YJ}$ ) and the extracted data were subsequently cross-checked. Discrepancies were discussed until a consensus was reached. The following information was extracted from each study: (1) first author, (2) year of publication, (3) study design, (4) research site (country), (5) total sample size, (6) type of epidemics of infectious diseases, (7) sex proportion of participants, (8) type of study population (patients, community population, and health care workers), and (9) measurement of stigma (question or scale), classification of stigma (enacted stigma, and perceived stigma), etc. (see Table 1).

\section{Assessment of study quality}

Two researchers (Huang XL and Su SZ) assessed the quality of the studies using the Australia's Joanna Briggs Institute (JBI) critical appraisal checklist for prevalence studies [34]. It consists of nine items, and four options (yes, no, unclear, and not applicable) were used for evaluating items (see eTable 2 in Appendix). Disagreements were discussed with and resolved by a third author (Zhang YX).

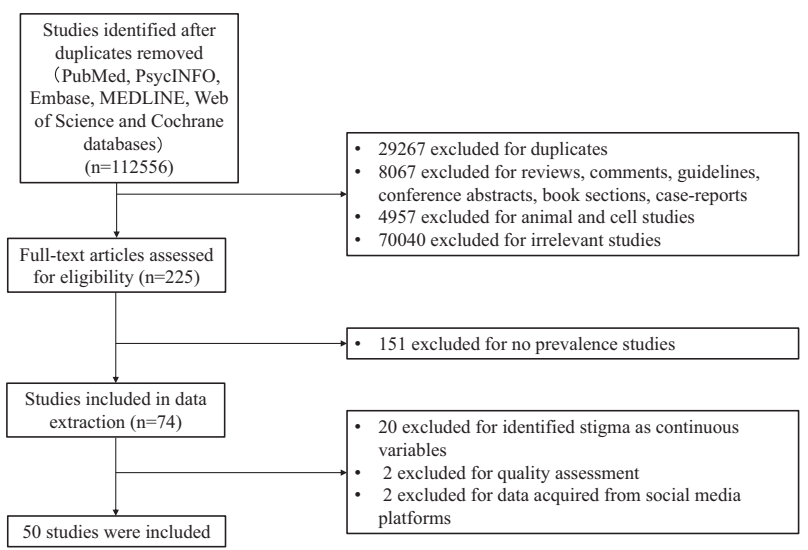

Fig. 1 Study selection flow diagram. We systematically searched the PubMed, PsycINFO, Embase, MEDLINE, Web of Science, and Cochrane databases to identify studies that reported the prevalence of stigma during infectious disease epidemics. A total of 112,556 articles were identified. After screening, 50 eligible studies were included in this meta-analysis. 


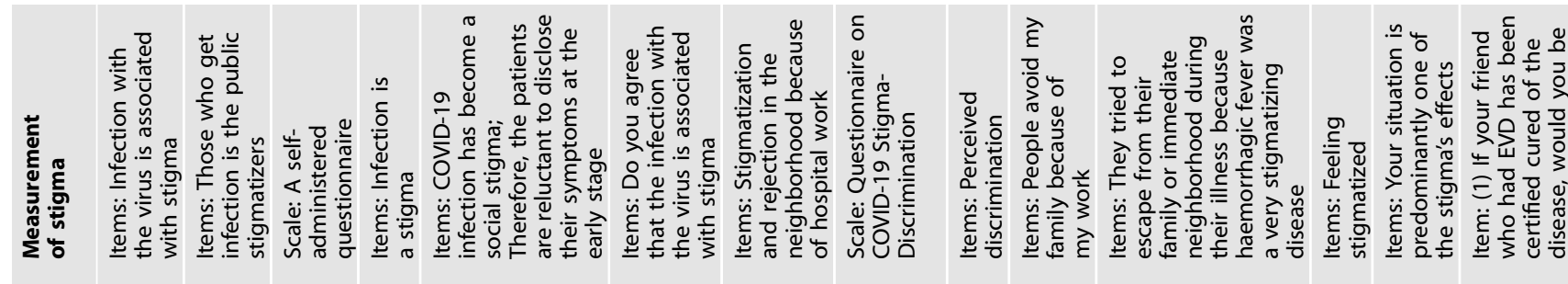

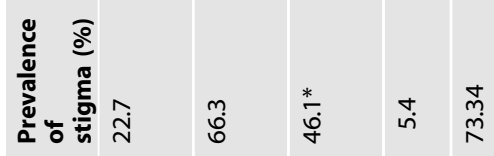

กี

苞

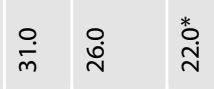

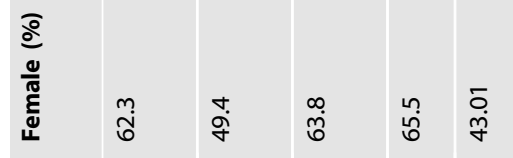

I.

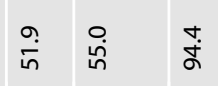

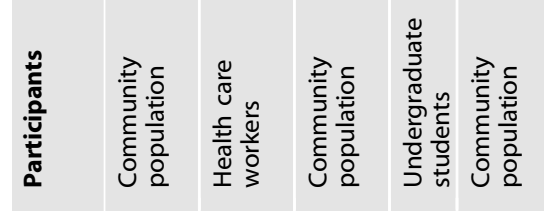

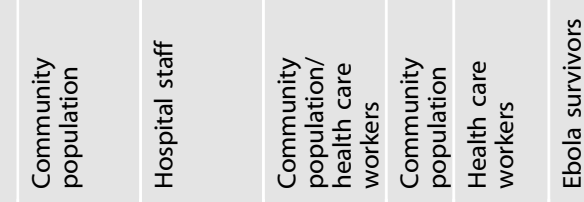

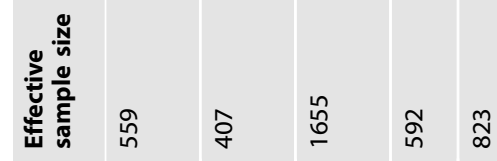

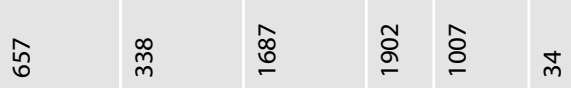

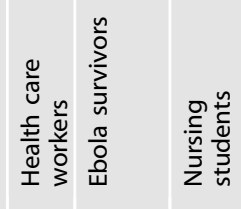

离

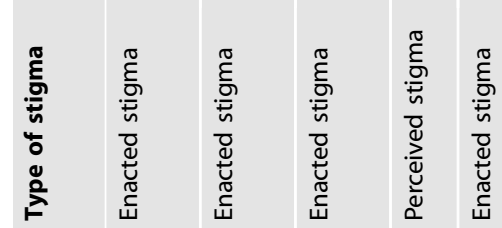

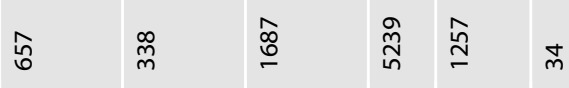

\&

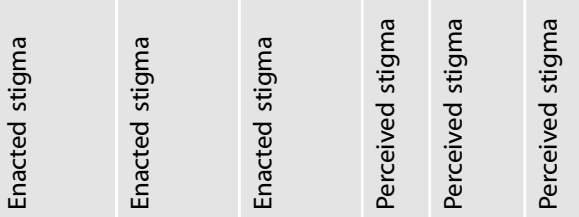

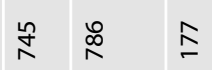

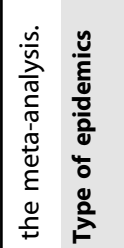

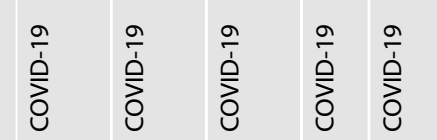

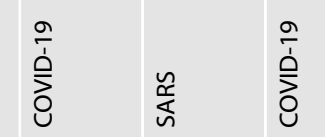

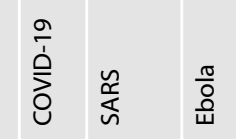

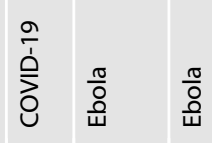

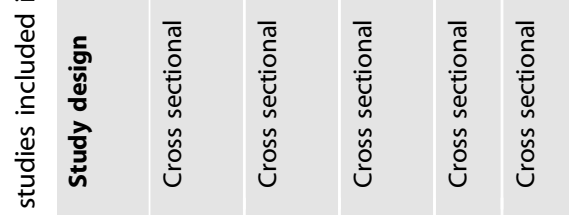

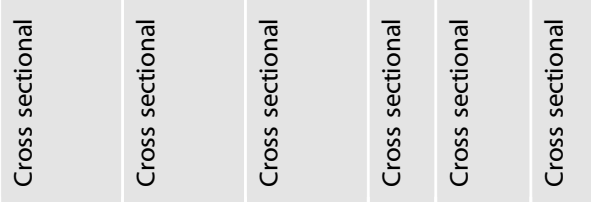

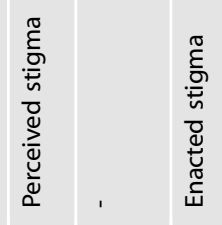

$\stackrel{0}{\stackrel{0}{ \pm}}$

I

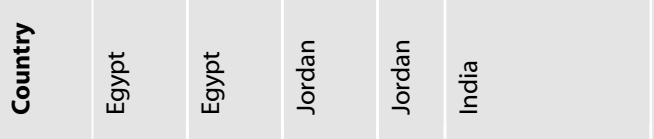

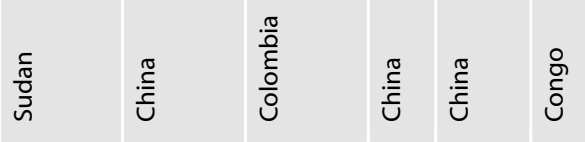

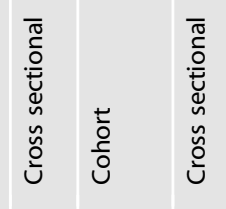

$\frac{\sqrt{\frac{\pi}{U}}}{\frac{\pi}{4}}$

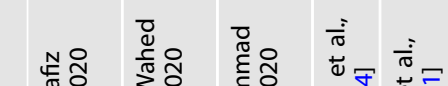

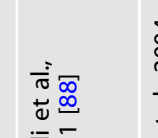

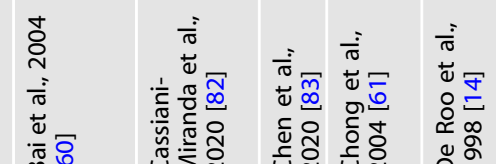

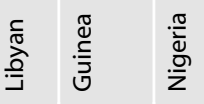

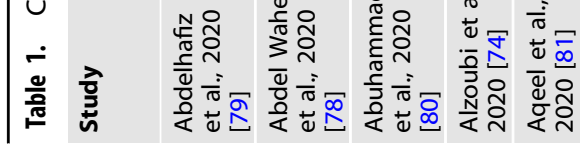

产

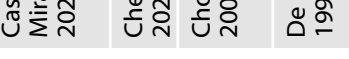

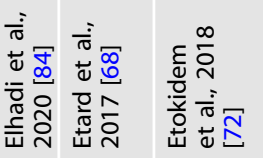




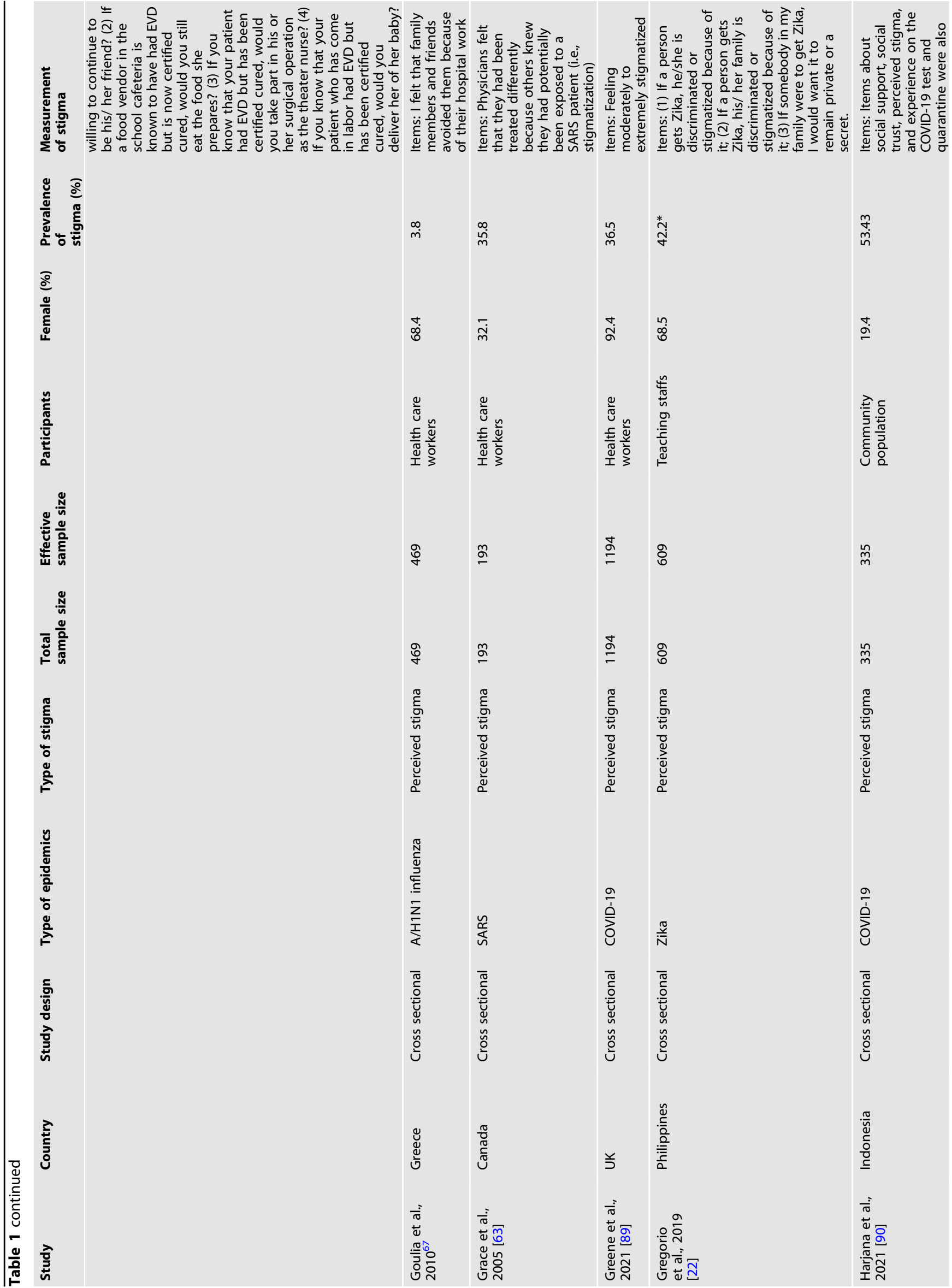




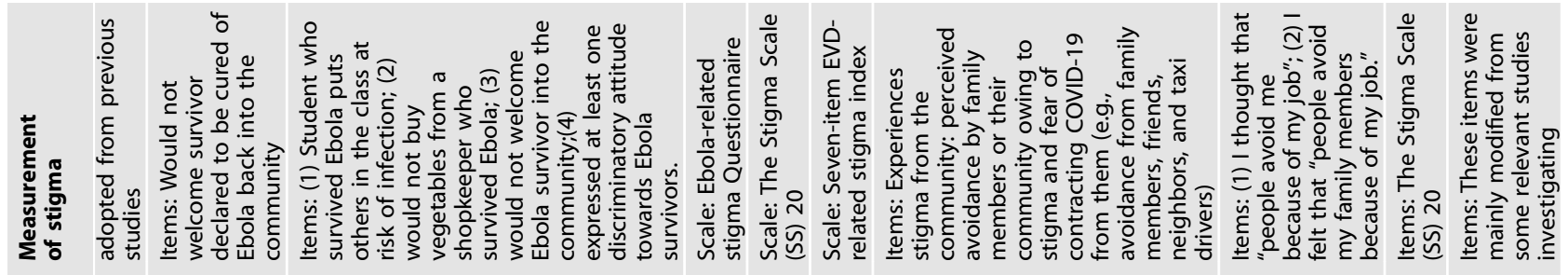

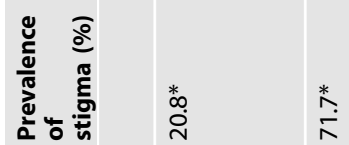

离

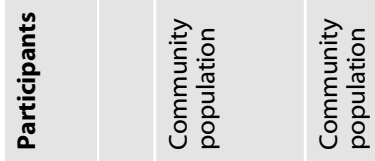

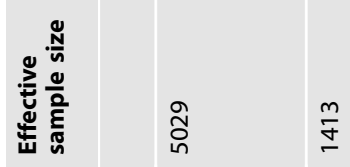

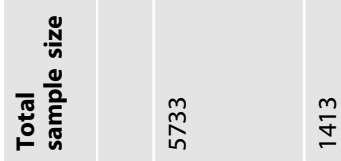

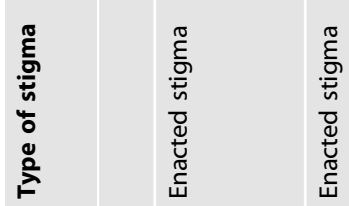

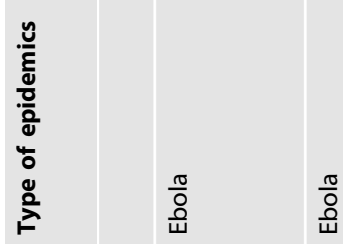

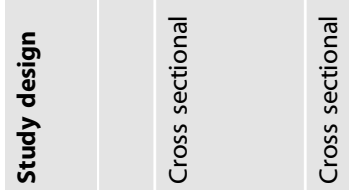

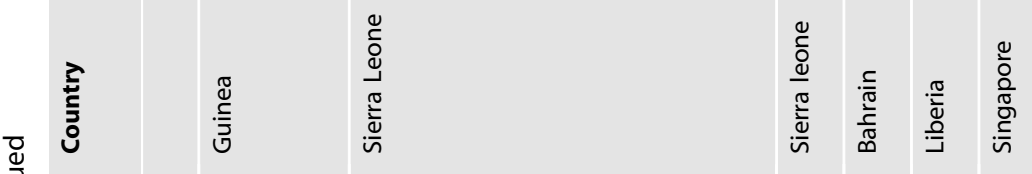

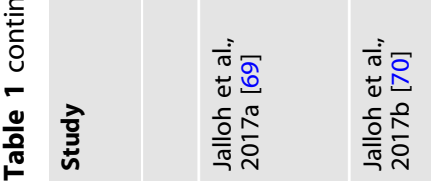

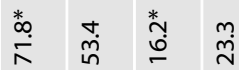

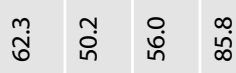

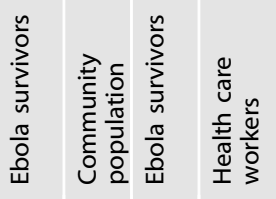

岗 î

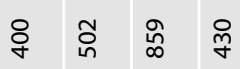

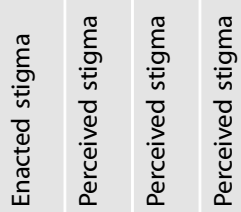

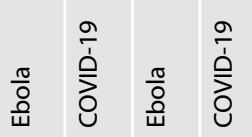

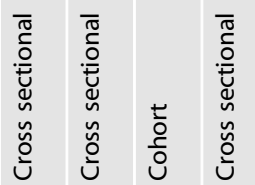

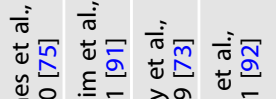

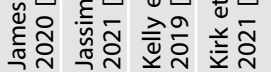

$\stackrel{m}{m} \stackrel{m}{m} \quad \bar{m}$

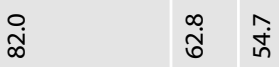

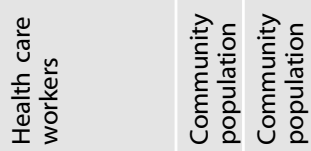

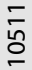

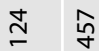

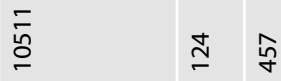

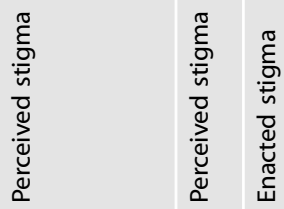

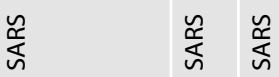

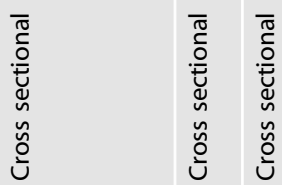

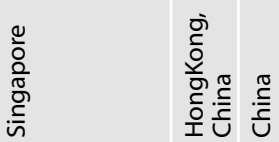

市守 

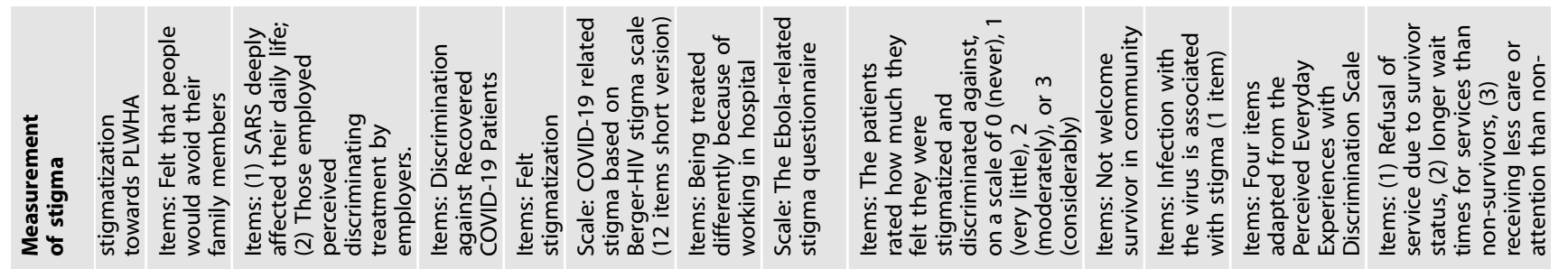

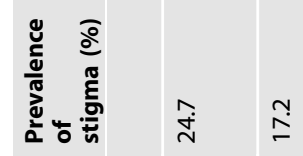

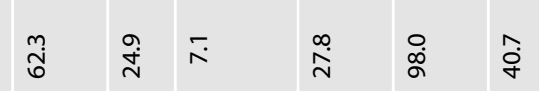

\begin{tabular}{ll|ll}
$\mathfrak{i}$ & $\hat{0}$ & $\infty$ & \multirow{+}{*}{} \\
& & $\stackrel{m}{\dot{m}}$
\end{tabular}

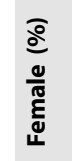

$\stackrel{\infty}{+} \stackrel{\circ}{\circ}$

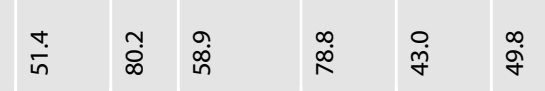

ํํ $\stackrel{m}{\stackrel{m}{n}} \stackrel{\text { in }}{\bar{m}}$

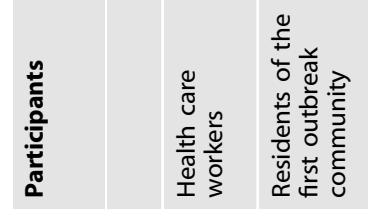

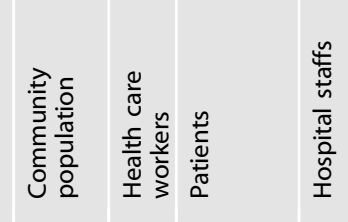

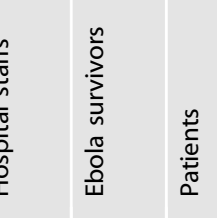

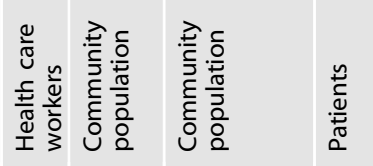

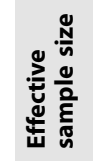

$\stackrel{\circ}{\circ}$

今ิ \&

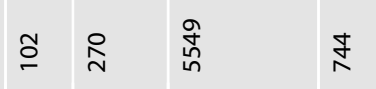

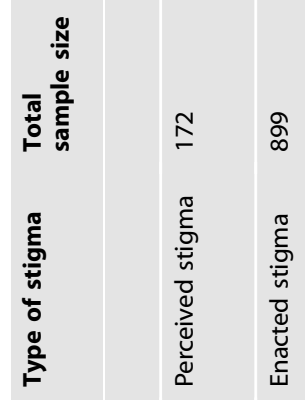

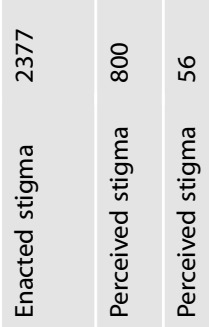

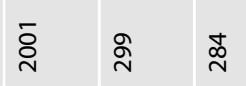

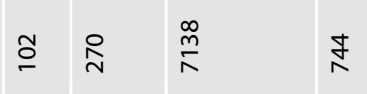

包

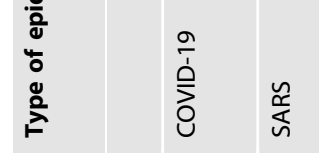

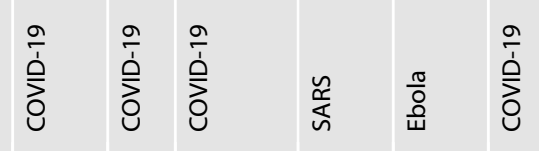

$\| \mathbb{I}$

111

!I

II

$\ln$

MI

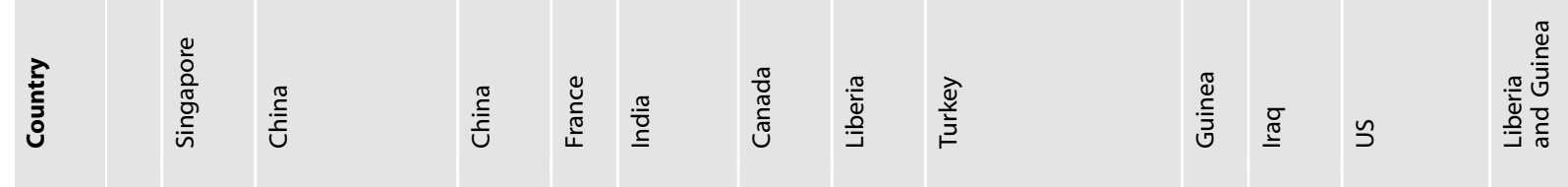




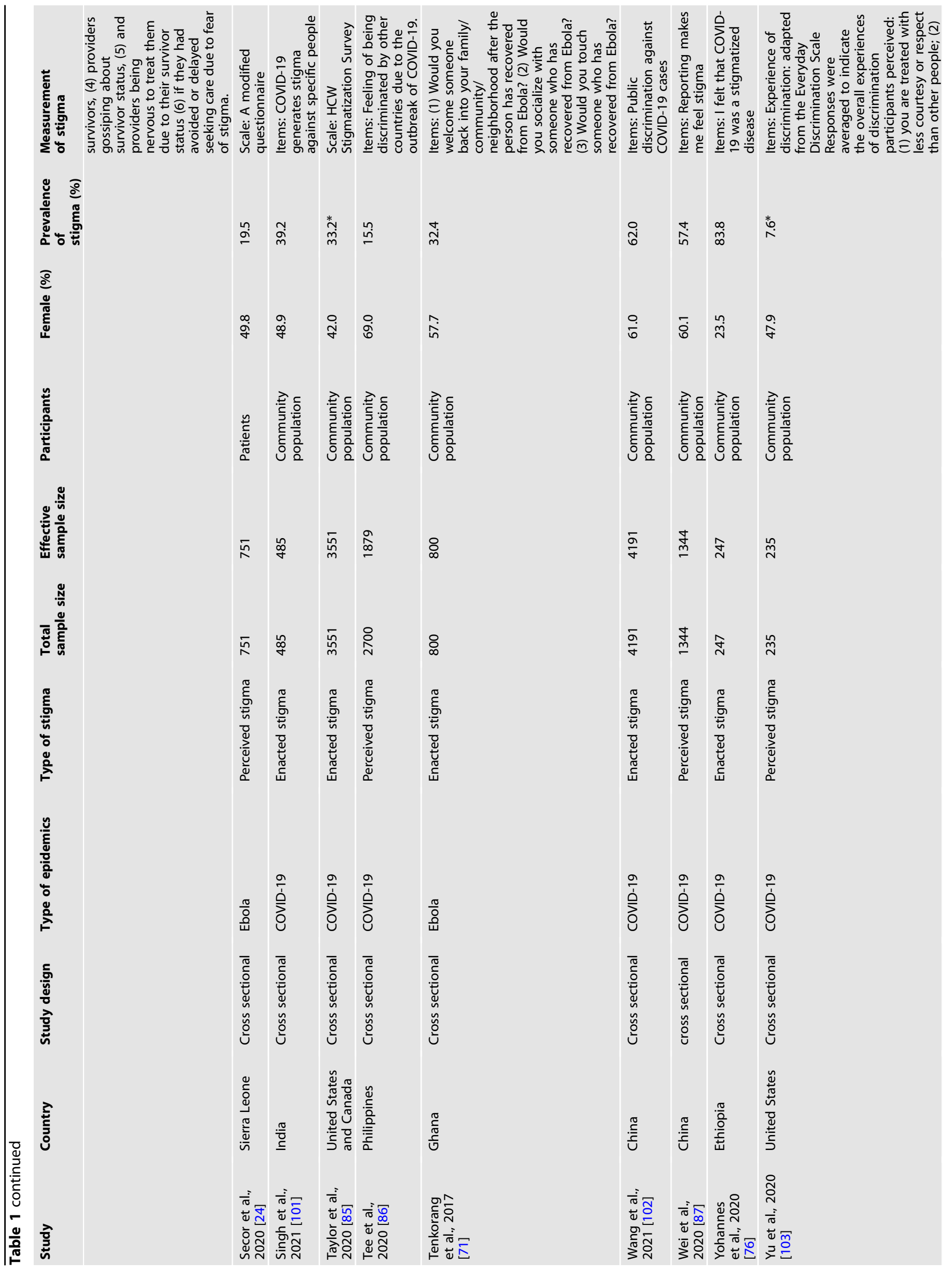




\section{Statistical analysis}

The primary outcomes of interest were the overall prevalence estimates of stigma which were calculated across all studies by using a random-effects model. Subgroups and meta-regression analyses were conducted to explore the potential sources of heterogeneity, including the following variables: study population, region, the levels of economic development, sex, and the proportion of tertiary education. $Q$ and $I$ [2] were calculated to assess heterogeneity across all studies and within subgroups, with $I^{2} \geq 50 \%$ indicating significant heterogeneity. Egger's test and the funnel plot were used to evaluate publication bias. A bilateral significance level less than 0.05 was considered to be statistically significant. All analyses were calculated with Stata version 15 .

\section{RESULTS}

A total of 112,556 articles were identified, of which 225 studies with full text were assessed for eligibility. We excluded 151 articles without stigma prevalence, 20 articles identifying stigma as continuous variables [35-54], two articles not meeting quality assessment $[55,56]$, and two articles with data from social media platforms $[57,58]$. Ultimately, 50 eligible studies were included in this meta-analysis. The complete PRISMA flow chart is shown in Fig. 1.

A total of 50 articles [14, 22, 24, 59-105] were included that contributed 51 estimates of prevalence in 92,722 participants. The basic characteristics of the studies are shown in Table 1. Overall, 10 studies focused on Ebola [14, 24, 59, 68-73, 75], eight studies on SARS [60-66, 93], 29 studies on COVID-19 [74, 76, 78-92, 94105], and the remaining three studies focused on H1N1 influenza [67], Zika [22], and Viral Haemorrhagic fevers [77], respectively. There was also a broad geographical and population distribution of included studies. There were 16 studies from Africa $[14,24,59,68-73,75-79,84,88], 25$ studies from Asia $[22,60,61,64-66,74,80,81,83,86,87,90-95,97-$ $99,101,102,104,105]$, and others were conducted in Europe $[67,89,96]$, North America [62, 63, 85, 100, 103] and South America [82]. More than half (27 studies) of the studies were conducted within community populations $[22,60,66,69-$ $72,74,76,79-81,83,85-88,90,91,93,95,99-104]$, while others consisted of health care workers (13 studies) $[60,61,63,64,67,77,78,84,89,92,94,96,105]$ and patients (eight studies) $[14,24,59,68,73,75,97,98]$. Of the 50 articles, 10 studies $[24,59,73,75,80,82,85,91,97,105]$ used modified scales for measuring stigma, while other studies measured the stigma by using one or more questions $[14,22,60-72,74,76-$ 79, 81, 83, 84, 86-90, 92-96, 98-104] (Table 1).

The pooled estimate of the prevalence of stigma across all studies was $34 \%$ [95\% Cl: $\left.28-40 \%, l^{2}=99.9 \%\right]$. We further analyzed the pooled prevalence based on the different populations. Three studies $[62,65,82]$ were not included in this subgroup analysis because of the lack of clear description of population type. Among the 47 articles that included 48 estimates of the prevalence of stigma in the population subgroups, the estimated prevalence was 38\% [95\% Cl: $12-65 \%$ ], 36\% [95\% Cl: $28-45 \%$ ], and $30 \%$ [95\% Cl: $20-40 \%$ ], in patients, community population, and health care workers, respectively (Fig. 2). The meta-regression analysis indicated that the pooled prevalence of stigma based on population had no significant difference $(p=0.684)$.

Subgroup analyses were performed with regard to stigma type, countries, type of infectious outbreak, gender, education level, and measurement tools (Fig. 3). In terms of stigma type, two studies $[59,68]$ were excluded because of no clear description of stigma types. Among the included 48 studies, 23 focused on enacted stigma (36\% [95\% Cl: $28-44 \%])$ and 25 on perceived stigma (31\% [95\% Cl: 22-40\%]) (Figs. 3 and S1). Meta-regression showed that the estimated prevalence based on types of stigma had no significant difference $(p=0.655)$.

Among health care workers, pooled prevalence of enacted stigma was $28 \%$ [95\% Cl: $0-57 \%$, while pooled prevalence of 


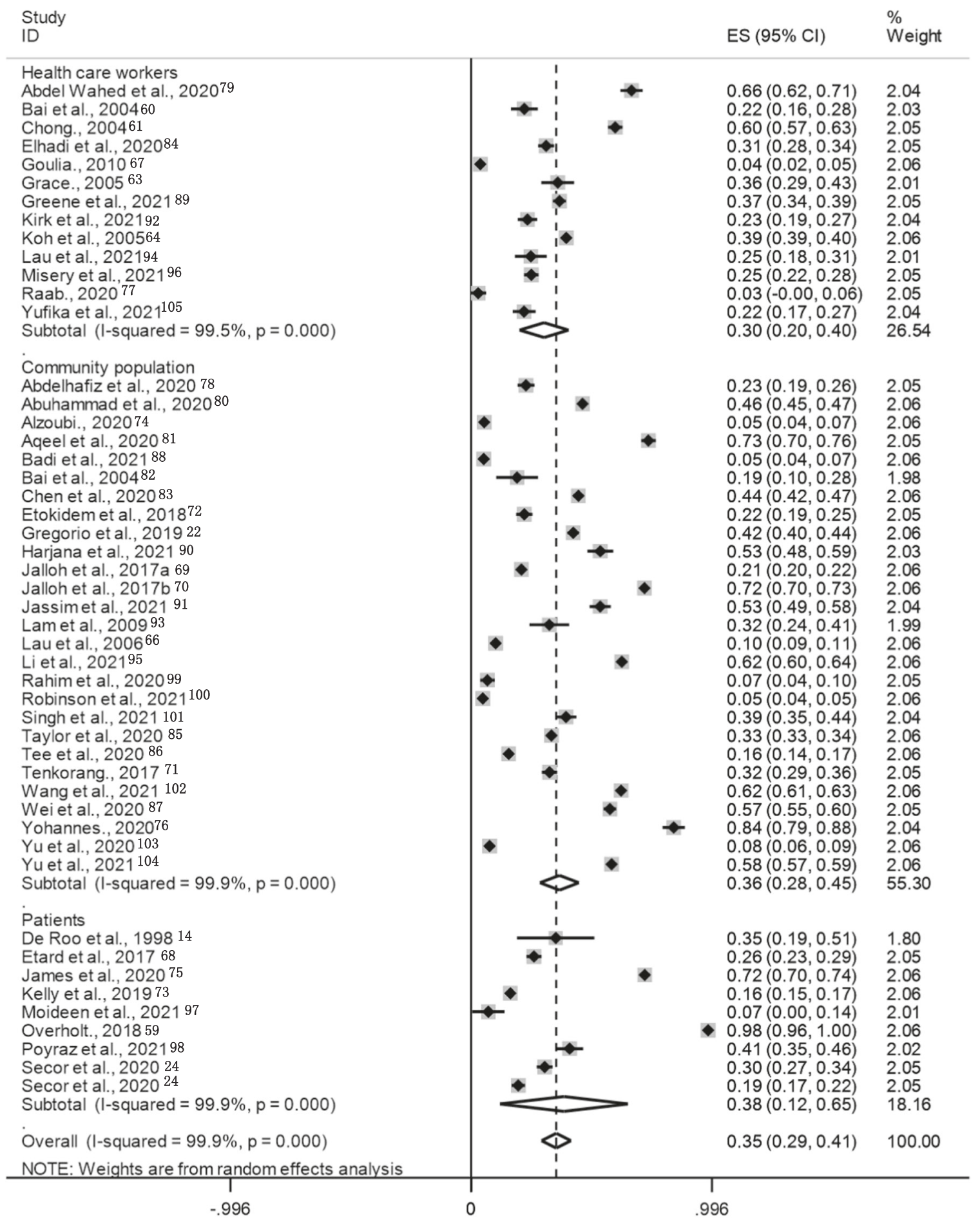

Fig. 2 Prevalence estimates by the study population. The estimated prevalence of stigma in patients, community population, and health care workers was $38 \%, 36 \%$, and $30 \%$, respectively. ES effect size (proportion), Cl confidence interval.

perceived stigma was 31\% [95\% Cl: $19-43 \%]$ ( $p=0.699)$. Among community population, the prevalence of enacted stigma was $38 \%$ [95\% Cl: $29-47 \%$ ], and the prevalence of perceived stigma was $34 \%$ [95\% Cl: $16-52 \%])(p=0.624)$ (Figs. 3 and S2). The estimated prevalence of stigma in low- and middle-income countries was $37 \%$ [95\% Cl: $29-45 \%]$, while the estimated prevalence of stigma from high-income countries was $27 \%$ [95\% $\mathrm{Cl}: 18-36 \%]$. However, the difference of prevalence of stigma between low- and middle-income countries and high-income countries was not statistically significant $(p=0.237)$ (Figs. 3 and
S3). The estimated prevalence of stigma in studies during the COVID-19, SARS, Ebola, and other infectious diseases was $35 \%$ [95\% Cl: 26-44\%], 30\% [95\% Cl: 20-40\%], 40\% [95\% Cl: 22-58\%], and $16 \%$ [95\% Cl: $0-43 \%$ ], respectively ( $p=0.737)$ (Figs. 3 and S4).

The pooled estimated prevalence of stigma in studies with a majority of female participants ( $\geq 50 \%$ ) was $30 \%$ [95\% Cl: $23-37 \%]$, lower than those studies with a minority $(<50 \%)$ of female participants $(46 \%$ [95\% Cl: $34-57 \%])$. However, this difference was not statistically significant ( $p=0.062$ ) (Figs. 3 and S5). In terms of the education level of participants, as twenty studies 


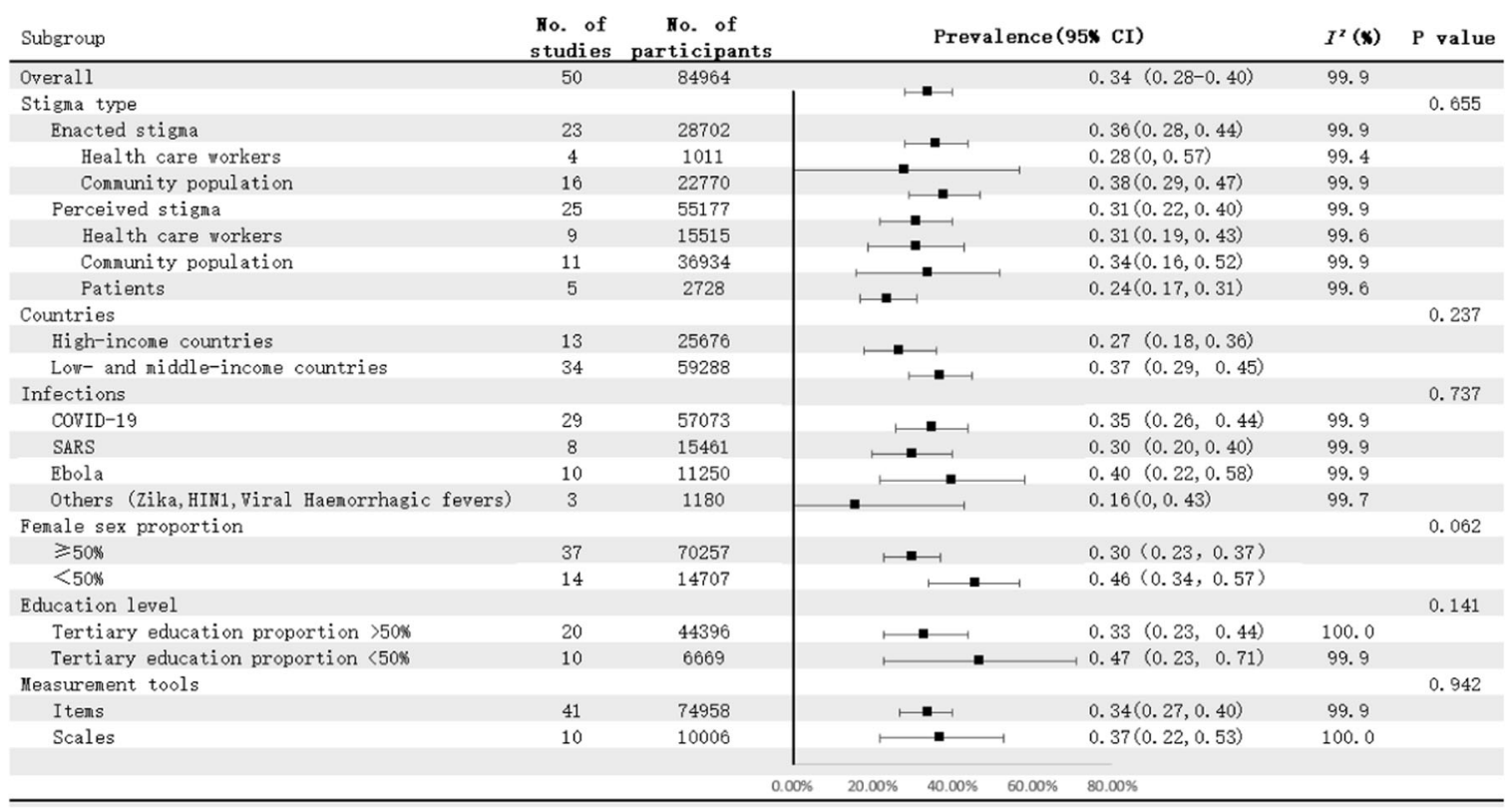

Fig. 3 Subgroup analysis of prevalence estimates across variables. We performed subgroup analyses with regard to stigma type, countries, type of infectious outbreak, gender, education level, and measurement tools. Meta-regression showed that the estimated prevalence based on different characteristics subgroup had no significant difference $(p>0.05)$.
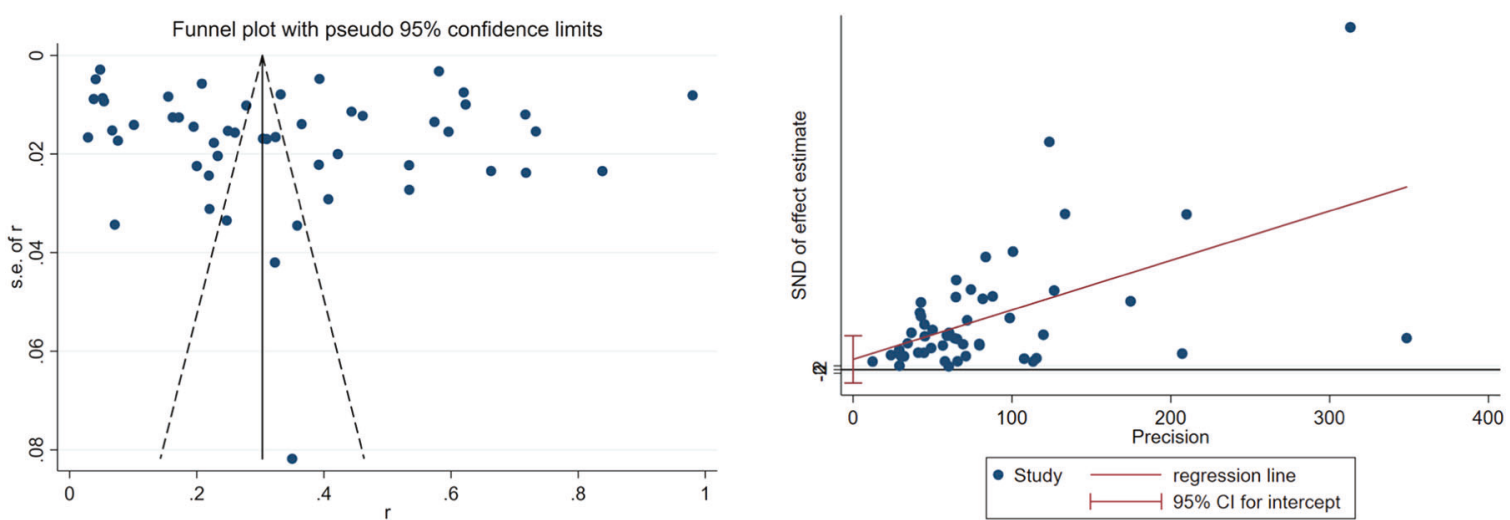

Fig. 4 Begg's funnel plot and Egger test. There was no publication bias suggested by Begg's funnel plot (left) and Egger test (right). $t=0.86$, $p=0.391$.

$[14,61,63-65,68-70,72,73,77,84,89,92,94,97,99,100,102,105]$ did not report educational levels or did not indicate tertiary education proportion, 30 studies were included in this subgroup analysis. We divided the studies into two groups according to the proportion of participants with tertiary education $(<50 \%$ and $\geq 50 \%$ ). The pooled estimated prevalence of stigma in studies with a minority $(<50 \%)$ of participants with tertiary education was $47 \%$ [95\% Cl: $23-71 \%]$, higher than those studies with a majority $(\geq 50 \%)$ of participants with tertiary education (33\% [95\% Cl: 23-44\%]). However, this difference was not statistically significant $(p=0.141)$ (Figs. 3 and S6).

As some studies included in our studies used items and the left used scales to measure stigma, we further performed subgroup analysis in terms of the measurement tools. Forty studies clearly described stigma items, and 10 studies used modified scales for measuring stigma. One study contributed two estimates of prevalence [24] (Table 1). The estimated prevalence of stigma was 34\% [95\% Cl: $27-40 \%$ ] in studies using items and 37\% [95\% $\mathrm{Cl}: 22-53 \%]$ in studies using scales, respectively. The metaregression analysis indicated that the pooled prevalence of stigma based on measurement tools had no significant difference ( $p=$ 0.942) (Figs. 3 and S7).
The Egger's tests and funnel plots (Fig. 4) did not show a publication bias $(p>0.05)$. A sensitivity analysis that was used for examining the impact of each study on the overall results showed similar estimates of stigma prevalence after excluding any single study, indicating that any study included in the present metaanalysis was unlikely to have a disproportionate impact on the reported prevalence estimates.

\section{DISCUSSION}

To our knowledge, this systematic review and meta-analysis provides the first quantitative estimate of stigma of affected individuals during infectious disease epidemics. We found that over a third of vulnerable populations reported infectious disease epidemic-related stigma, mainly involving infected patients, community members, and health care workers. People from low- and middle-income countries or with lower education are vulnerable populations who may have a greater risk of reporting stigma (enacted stigma or perceived public stigma). The results indicate that stigma is a significant public health concern during infectious disease epidemics, including COVID-19, and calls for actions to raise public health concern and develop effective and 
comprehensive interventions to reduce infectious disease-related stigma.

The rapid spread of an epidemic is typically associated with high levels of fear, which is manifested as stigma of and discrimination against affected individuals. Stigma can be a hindrance for the public to have an accurate understanding of the disease and can impose an adverse effect on the control of infectious disease epidemics. For example, during the COVID-19 epidemic, patients were reluctant to disclose their symptoms and see doctors at the early stage when COVID-19 became a social stigma [81]. Patients recovered from COVID-19 infections were even denied to take public transportation, assaulted on the street, or interfered with in their normal work [15, 16], which might increase their psychological stress and negatively affect the control of the pandemic. Although there is limited information in the extant literature, effective and accurate educational interventions and protecting policies of affected individuals are needed to counteract the damaging effects of infectious diseaserelated stigma, promote the control of infectious diseases, improve public mental and physical health, and facilitate the social stability and development ultimately.

Stigma was commonly reported by patients, community population, and health care workers during the epidemics, which can have a long-term adverse impact on their well-being and willingness to engage with health care. In the general population, enacted stigma (36\%) was a little higher than their perceived stigma (31\%). This could mean that perceptions were optimistic, underestimating the prevalence of enacted stigma that actually occurred. In community populations, the prevalence was $38 \%$ for enacted stigma, and $34 \%$ for perceived stigma, respectively. Residents living in places where the outbreak first occurred would be accused of spreading the virus, considered infectious, and thus further subjected to discrimination and stigmatization [83, 106]. On the other hand, people may endorse stigma when accepting survivors back into communities. However, variance in epidemicrelated stigma across communities exists and some communitylevel factors may account for this. For example, communities with higher knowledge of the disease and high mobilization efforts were less likely to endorse stigma, while communities that were concerned about providing assistance and care during the epidemics were more likely to endorse stigma (i.e., enacted stigma) $[71,107]$. Community-level interventions are needed to increase awareness and knowledge of the epidemics among community populations.

The high prevalence of enacted stigma (28\%) and perceived stigma (31\%) among health care workers also indicated that they not only expressed discrimination against some particular groups related to infectious diseases, but also were discriminated more seriously by the general public. During the epidemic of infectious diseases, health care workers are at high risk of infection. Physical and mental exhaustion, fear of infection, worries about passing the infection to their friends and families, as well as medical violence (the conflicting doctor-patient relationship, especially in China) during the pandemic of COVID-19 were main complaints of medical workers [108-110]. Moreover, an increasing proportion of medical staffs reported suffering from isolation and avoidance from the community population. They described the feelings of rejection in their neighborhood because of hospital work or the feelings of being treated differently because others knew they might have contacted patients with infectious diseases $[60,64]$. The stigma they experienced had adverse effects on their mental health. Therefore, more social support policies and mental health services are urgently needed for health care workers to protect their wellbeing and effectively control the epidemics.

The finding that individuals with higher levels of education had a lower prevalence of stigma is consistent with our expectations, though no significant difference was observed possibly due to the limited number and heterogeneity of studies included. An overabundance of news and mixed messages is a key driver of stigma in our time, especially during large-scale disasters like COVID-19 [111-113]. With a higher level of education, individuals may have better access to accurate knowledge about infectious diseases and have a better understanding of the situation, so that they could distinguish between factual information and misinformation. This may be more difficult for those with lower education level, who may be more easily misled by biased or false information provided by traditional media, social media, and self-proclaimed experts [114]. As previous studies reported, education, clear and correct communication have the potential to significantly improve the knowledge, attitudes, and behaviors related to infectious diseases, such as Ebola and COVID-19, and reduce infectious disease-related stigma $[115,116]$. Therefore, it is important to improve public awareness of the nature of the disease to reduce fear and anxiety, and subsequently reduce the stigma [117]. In addition, the higher educational level is always associated with high socio-economic status, which could explain the fact that people with higher income level may be less worried and less likely to stigmatize others, especially in high-income countries [118]. However, there were few studies on infectious disease-related stigma from high-income countries, and more studies are needed in the future.

Differences in infectious disease-related stigma hinge on the features related to infectious diseases. Among various infectious diseases, stigma related to human immunodeficiency virus/ acquired immunodeficiency syndrome (HIV/AIDS) has been the most salient and widely studied [119]. However, in our present study, we excluded the infectious diseases like HIV/AIDS that do not cause an outbreak. Compared with infectious diseases like SARS and COVID-19, the means of infection and disease course of HIV/AIDS differ substantially [120]. HIV/AIDS has been perceived as a fatal condition with little hope of recovery since the infection [8], while epidemic-related infectious diseases may be cured by antiviral medications or controlled just by physical distancing. Therefore, the disease course of HIV/AIDS is chronic, while that of epidemic-related infectious diseases is usually acute and timelimited. Furthermore, HIV/AIDS is always being stigmatized with negative connotations such as drug abuse, sex work, poverty, or incarceration, which are considered to be deviant and disapproved by the society [121]. In contrast, epidemic-related diseases such as SARS and COVID-19 are caused mainly by external factors that are not considered as morally reprehensible. Therefore, stigmatization of these infectious diseases is mainly driven by the fear of the disease itself, and will be reduced as the perceived threat level decreases $[26,65]$.

To tackle social stigma derived from infectious disease epidemics, many health authorities and academic associations across the world have appealed to stop stigmatizing and discriminating against certain populations, such as survivors and those from high-risk areas [122, 123], highlighting the negative consequences of stigma that compromise efforts to treat the disease and reduce its further transmission. As COVID-19 is still a continuing threat for the human society, several crucial actions are needed to reduce COVID-19-related stigma. First, governments and authorities need to work closely to stop racism and xenophobia toward specific countries and areas at high epidemic level [124]. Evidence shows that disease outbreaks have always been accompanied by an increase in xenophobic or racist sentiment [125]. The COVID-19 is a global public health issue and united efforts are crucial to win the worldwide battle against it. Second, proper public health education with scientific-based information and an anti-stigma campaign appear to be the most effective ways to prevent social harassment of at-risk groups $[13,126]$. This would also help create an appropriate environment to work together to contain this pandemic. Third, the government and health authorities should appeal for the public to access COVID-19 information from reliable sources like the Centers for 
Disease Control and Prevention (CDC) and the World Health Organization (WHO). Fourth, community leaders and public health officials should maintain the privacy and confidentiality of survivors, avoid using negative languages that may cause stigmatization, and provide community and social support to challenge stereotypes and stigmatization [123]. Fifth, more research using scales to estimate the prevalence of stigma are needed and more standardized scales should be developed for routine assessment of infectious disease-related stigma in at-risk groups and necessary support should be provided for those who may feel stigmatized [127]. Last but not least, the long-term impact of COVID-19 on stigma should be examined and the effectiveness of protection measures and interventions should be explored in further studies.

This study had several limitations that compromise the interpretation of the findings. First, the lack of reliable and valid instruments of infectious disease-related stigma used in the populations studied is a major limitation for both research and practice. Only 10 studies $[24,59,73,75,80,82,85,91,97,105]$ used modified scales for measuring stigma. And these measure tools, such as the Ebola-related stigma Questionnaire, seven-item EVDrelated stigma index, varied widely in terms of measurement development, the groups surveyed and the domains assessed (i.e., knowledge, attitude, and behavior). Moreover, other studies without valid scales measured the prevalence of infectious disease-related stigma by using one or more items. We defined the (combined) proportion of "Yes" of one item or several items in studies as the (combined) prevalence of stigma in these studies. Standardized scales should be developed to assess infectious disease-related stigma in further studies. Second, although we initially searched for all major infectious disease epidemics, the majority of eligible studies (47 out of 50) mainly focused on Ebola, SARS, and COVID-19, resulting in insufficient data to allow subgroup analysis of the prevalence of stigma in other infectious diseases. Furthermore, the literature search in the present study was limited to English, which may omit some useful studies related to the stigmatization of infectious diseases in other languages. Finally, there was high heterogeneity in the estimated prevalence of stigma with an $I^{2}$ of more than $99 \%$, possibly because of the vastly diverse and non-standardized scales used in the included studies as mentioned above. Furthermore, we also took measures to find out other sources of heterogeneity, including using random-effect models, subgroup analysis, and meta-regression analysis. Sensitivity analyses were also conducted to identify the influence of individual studies on the pooled estimates by excluding each of the studies from the pooled estimate. Nonetheless, the remaining unexplained heterogeneity was still substantial. More research is needed to provide us with more accurate information about the prevalence of infectious disease-related stigma.

\section{CONCLUSIONS}

In conclusion, individuals reported infectious disease-related stigma, including enacted stigma and perceived stigma, exceeded one-third, with the highest prevalence of stigma observed in infected patients, followed by community populations and health care workers. Our findings indicate that infectious disease-related stigma is a significant public health concern during infectious disease epidemics, including COVID-19. Governments and public health authorities need to pay more attention to take comprehensive and effective measures and strategies to eliminate or reduce threats of infectious disease-related stigma.

\section{REFERENCES}

1. World Health Organization. Coronavirus Disease (COVID-19) pandemic. 2020. https://www.who.int/emergencies/diseases/novel-coronavirus-2019. Accessed 14 Dec 2020.
2. Bedford J, Farrar J, Ihekweazu C, Kang G, Koopmans M, Nkengasong J. A new twenty-first century science for effective epidemic response. Nature. 2019;575:130-6.

3. Bao Y, Sun Y, Meng S, Shi J, Lu L. 2019-nCoV epidemic: address mental health care to empower society. Lancet. 2020;395:e37-e38.

4. Shi L, Lu ZA, Que JY, Huang XL, Liu L, Ran MS, et al. Prevalence of and risk factors associated with mental health symptoms among the general population in China during the Coronavirus Disease 2019 pandemic. JAMA Netw Open. 2020;3:e2014053.

5. Liu JJ, Bao Y, Huang X, Shi J, Lu L. Mental health considerations for children quarantined because of COVID-19. Lancet Child Adolesc Health. 2020;4:347-9.

6. Lau JT, Yang X, Pang E, Tsui HY, Wong E, Wing YK. SARS-related perceptions in Hong Kong. Emerg Infect Dis. 2005;11:417-24.

7. Link BG, Phelan JC. Conceptualizing stigma. Annu Rev Socio. 2001;27:363-85.

8. Malcolm A, Aggleton P, Bronfman M, Galv OJ, Mane P, Verrall J. HIV-related stigmatization and discrimination: its forms and contexts. Crit Public Health. 1998;8:347-70

9. Uvais NA, Aziz F, Hafeeq B. COVID-19-related stigma and perceived stress among dialysis staff. J Nephrol. 2020;33:1121-2.

10. Goffman E. Stigma: notes on the management of spoiled identity. Englewood Cliffs: Prentice Hall, Inc; 1969 642pp.

11. Algarin $A B$, Sheehan DM, Varas-Diaz N, Fennie KP, Zhou Z, Spencer EC, et al. Health care-specific enacted HIV-related stigma's association with antiretroviral therapy adherence and viral suppression among people living with HIV in Florida. AIDS Patient Care STDS. 2020;34:316-26.

12. Wolitski RJ, Pals SL, Kidder DP, Courtenay-Quirk C, Holtgrave DR. The effects of HIV stigma on health, disclosure of HIV status, and risk behavior of homeless and unstably housed persons living with HIV. AIDS Behav. 2009;13:1222-32.

13. Bagcchi S. Stigma during the COVID-19 pandemic. Lancet Infect Dis. 2020;20:782.

14. De Roo A, Ado B, Rose B, Guimard Y, Fonck K, Colebunders R. Survey among survivors of the 1995 Ebola epidemic in Kikwit, Democratic Republic of Congo: their feelings and experiences. Trop Med Int Health. 1998;3:883-5.

15. Caldera-Villalobos C, Garza-Veloz I, Martínez-Avila N, Delgado-Enciso I, OrtizCastro Y, Cabral-Pacheco GA, et al. The Coronavirus Disease (COVID-19) challenge in Mexico: a critical and forced reflection as individuals and society. Front Public Health. 2020;8:337.

16. Rubio L. México Debe Cuidar a sus Médicos y Enfermeras, no Atacarlos. 2020. https://www.unotv.com/videoblogs/opinion/luis-rubio/detalle/por-coronavirusen-mexico-atacan-a-medicos-y-enfermeras-479161/. Accessed 18 Feb 2021.

17. Courtemanche C, Garuccio J, Le A, Pinkston J, Yelowitz A. Strong social distancing measures in the United States reduced the COVID-19 growth rate. Health Aff (Millwood). 2020;39:1237-46.

18. Li JQ, Wang YH, Lu QD, Xu YY, Bao YP. Prevalence of psychological distress in type ii diabetes in China: a systematic review and meta-analysis. Heart Mind. 2019;3:147.

19. Sun Y, Bao Y, Ravindran A, Sun Y, Lu L. Mental health challenges raised by rapid socioeconomic transformations in China: lessons learned and prevention strategies. Heart. Mind. 2020;4:59.

20. Marbán-Castro $E$, Villén-Gonzalvo $A$, Enguita-Fernàndez $C$, Marín-Cos A, Menéndez $C$, Maixenchs $M$, et al. Uncertainties, fear and stigma: perceptions of Zika Virus among pregnant women in Spain. Int J Environ Res Public Health. 2020;17:E6643.

21. Park HY, Park WB, Lee SH, Kim JL, Lee JJ, Lee $H$, et al. Posttraumatic stress disorder and depression of survivors 12 months after the outbreak of Middle East respiratory syndrome in South Korea. BMC Public Health. 2020;20:605

22. Gregorio ER Jr., Medina JRC, Lomboy MFTC, Talaga ADP, Hernandez PMR, Kodama $\mathrm{M}$, et al. Knowledge, attitudes, and practices of public secondary school teachers on Zika Virus Disease: a basis for the development of evidence-based Zika educational materials for schools in the Philippines. PLoS One. 2019;14: e0214515.

23. Yuan K, Gong YM, Liu L, Sun YK, Tian SS, Wang YJ et al. Prevalence of posttraumatic stress disorder after infectious disease pandemics in the twenty-first century, including COVID-19: a meta-analysis and systematic review. Mol Psychiatry. 2021. https://doi.org/10.1038/s41380-021-01036-x.

24. Secor A, Macauley R, Stan L, Kagone M, Sidikiba S, Sow S, et al. Mental health among Ebola survivors in Liberia, Sierra Leone, and Guinea: results from a crosssectional study. BMJ Open. 2020;10:e035217.

25. Siu JY. The SARS-associated stigma of SARS victims in the post-SARS era of Hong Kong. Qual Health Res. 2008;18:729-38.

26. Person B, Sy F, Holton K, Govert B, Liang A. Fear and stigma: the epidemic within the SARS outbreak. Emerg Infect Dis. 2004;10:358-63.

27. Duan W, Bu H, Chen Z. COVID-19-related stigma profiles and risk factors among people who are at high risk of contagion. Soc Sci Med. 2020;266:113425. 
28. Huang C, Wang Y, Li X, Ren L, Zhao J, Hu Y, et al. Clinical features of patients infected with 2019 novel coronavirus in Wuhan, China. Lancet. 2020;395:497-506.

29. Wang Y, Shi L, Que J, Lu Q, Liu L, Lu Z et al. The impact of quarantine on mental health status among general population in China during the COVID-19 pandemic. Mol Psychiatry. 2021. https://doi.org/10.1038/s41380-021-01019-y.

30. Dubey S, Biswas P, Ghosh R, Chatterjee S, Dubey MJ, Chatterjee S, et al. Psychosocial impact of COVID-19. Diabetes Metab Syndr. 2020;14:779-88.

31. Clement S, Schauman O, Graham T, Maggioni F, Evans-Lacko S, Bezborodovs N, et al. What is the impact of mental health-related stigma on help-seeking? A systematic review of quantitative and qualitative studies. Psychol Med. 2015;45:11-27.

32. Chesney MA, Smith AW. Critical delays in HIV testing and care: the potential role of stigma. Am Behav Sci. 1999;42:1162-74.

33. Moher D, Liberati A, Tetzlaff J, Altman DG, Grp P. Preferred reporting items for systematic reviews and meta-analyses: the PRISMA statement. PLoS Med. 2009;6:6.

34. Munn Z, Moola S, Lisy K, Riitano D, Tufanaru C. Methodological guidance for systematic reviews of observational epidemiological studies reporting prevalence and cumulative incidence data. Int J Evid Based Health. 2015;13:147-53.

35. Maunder RG, Lancee WJ, Rourke S, Hunter JJ, Goldbloom D, Balderson K, et al. Factors associated with the psychological impact of severe acute respiratory syndrome on nurses and other hospital workers in Toronto. Psychosom Med. 2004;66:938-42.

36. Choi JS, Kim JS. Factors influencing emergency nurses' ethical problems during the outbreak of MERS-CoV. Nurs Ethics. 2018;25:335-45.

37. Ho SM, Kwong-Lo RS, Mak CW, Wong JS. Fear of severe acute respiratory syndrome (SARS) among health care workers. J Consult Clin Psychol. 2005;73:344-9.

38. Prati G, Pietrantoni L. Knowledge, risk perceptions, and xenophobic attitudes: evidence from Italy during the Ebola outbreak. Risk Anal. 2016;36:2000-10.

39. Park JS, Lee EH, Park NR, Choi YH. Mental health of nurses working at a government-designated hospital during a MERS-CoV outbreak: a cross-sectional study. Arch Psychiatr Nurs. 2018;32:2-6.

40. Verma S, Mythily S, Chan YH, Deslypere JP, Teo EK, Chong SA. Post-SARS psychological morbidity and stigma among general practitioners and traditional Chinese medicine practitioners in Singapore. Ann Acad Med Singap. 2004;33:743-8.

41. Mak IW, Chu CM, Pan PC, Yiu MG, Ho SC, Chan VL. Risk factors for chronic posttraumatic stress disorder (PTSD) in SARS survivors. Gen Hosp Psychiatry. 2010;32:590-8

42. Cénat JM, Dalexis RD, Guerrier M, Noorishad PG, Derivois D, Bukaka J, et al. Frequency and correlates of anxiety symptoms during the COVID-19 pandemic in low- and middle-income countries: a multinational study. J Psychiatr Res. 2021;132:13-17.

43. Cénat JM, Mclntee SE, Guerrier M, Derivois D, Rousseau C, Dalexis RD, et al. Psychological distress among adults from the urban and rural areas affected by the Ebola virus disease in the Democratic Republic of the Congo. Soc Psychiatry Psychiatr Epidemiol. 2021;56:57-62.

44. Cenat JM, Noorishad P-G, Kokou-Kpolou CK, Dalexis RD, Hajizadeh S, Guerrier M, et al. Prevalence and correlates of depression during the COVID-19 pandemic and the major role of stigmatization in low- and middle-income countries: a multinational cross-sectional study. Psychiatry Res. 2021;297:113714.

45. Chew QH, Chia FLA, Ng WK, Lee WCl, Tan PLL, Wong CS, et al. Perceived stress, stigma, traumatic stress levels, and coping responses amongst residents in training across multiple specialties during Covid-19 pandemic - a longitudinal study. Int J Environ Res Public Health. 2020;17:1-13.

46. Dang AK, Le XTT, Le HT, Tran BX, Do TT, Phan HTB, et al. Evidence of covid-19 impacts on occupations during the first Vietnamese national lockdown. Ann Glob Health. 2020;86:1-9.

47. Dar SA, Khurshid SQ, Wani ZA, Khanam A, Haq I, Shah NN, et al. Stigma in coronavirus disease-19 survivors in Kashmir, India: a cross-sectional exploratory study. PLoS One. 2020;15:e0240152.

48. Kalichman SC, El-Krab R, Shkembi B, Kalichman MO, Eaton LA. Prejudicial beliefs and COVID-19 disruptions among sexual minority men living with and not living with HIV in a high SARS-CoV-2 prevalence area. Transl Behav Med. 2021. https:// doi.org/10.1093/tbm/ibab050.

49. Kang E, Lee SY, Kim MS, Jung H, Kim KH, Kim K-N, et al. The psychological burden of COVID-19 stigma: evaluation of the mental health of isolated mild condition COVID-19 patients. J Korean Med Sci. 2021;36:e33.

50. Lee ES, Tan SY, Lee PSS, Koh HL, Soon SWW, Sim K et al. Perceived stress and associated factors among healthcare workers in a primary healthcare setting: the Psychological Readiness and Occupational Training Enhancement during COVID-19 Time (PROTECT) study. Singapore Med J. 2020. https://doi.org/ 10.11622/smedj.2020163.
51. Paleari FG, Pivetti M, Galati D, Fincham FD. Hedonic and eudaimonic well-being during the COVID-19 lockdown in Italy: the role of stigma and appraisals. $\mathrm{Br} J$ Health Psychol. 2021;26:657-78.

52. Tasnim R, Sujan MSH, Islam MS, Ritu AH, Siddique MAB, Toma TY, et al. Prevalence and correlates of anxiety and depression in frontline healthcare workers treating people with COVID-19 in Bangladesh. BMC Psychiatry. 2021;21:271.

53. Yoon $\mathrm{H}$, You M, Shon C. Peritraumatic distress during the COVID-19 pandemic in Seoul, South Korea. Int J Environ Res Public Health. 2021;18:4689.

54. Xin M, Luo S, She R, Yu Y, Li L, Wang S, et al. Negative cognitive and psychological correlates of mandatory quarantine during the initial COVID-19 outbreak in China. Am Psychol. 2020;75:607-17.

55. Belfroid E, Mollers M, Smit PW, Hulscher M, Koopmans M, Reusken $C$, et al. Positive experiences of volunteers working in deployable laboratories in West Africa during the Ebola outbreak. PLoS One. 2018;13:e0196320.

56. He J, He L, Zhou W, Nie X, He M. Discrimination and social exclusion in the outbreak of COVID-19. Int J Environ Res Public Health. 2020;17:2933.

57. Panigrahi M, Pattnaik JI, Padhy SK, Menon V, Patra S, Rina K, et al. COVID-19 and suicides in India: a pilot study of reports in the media and scientific literature. Asian J Psychiatr. 2021;57:102560.

58. Shoib S, Nagendrappa S, Grigo O, Rehman S, Ransing R. Factors associated with COVID-19 outbreak-related suicides in India. Asian J Psychiatr. 2020;53:102223.

59. Overholt L, Wohl DA, Fischer WA II, Westreich D, Tozay S, Reeves E, et al. Stigma and Ebola survivorship in Liberia: results from a longitudinal cohort study. PLoS One. 2018;13:e0206595.

60. Bai Y, Lin CC, Lin CY, Chen JY, Chue CM, Chou P. Survey of stress reactions among health care workers involved with the SARS outbreak. Psychiatr Serv. 2004;55:1055-7.

61. Chong M-Y, Wang W-C, Hsieh W-C, Lee C-Y, Chiu N-M, Yeh W-C, et al. Psychological impact of severe acute respiratory syndrome on health workers in a tertiary hospital. Br J Psychiatry. 2004;185:127-33.

62. Nickell LA, Crighton EJ, Tracy CS, Al-Enazy H, Bolaji Y, Hanjrah S, et al. Psychosocial effects of SARS on hospital staff: survey of a large tertiary care institution. CMAJ. 2004;170:793-8.

63. Grace SL, Hershenfield K, Robertson E, Stewart DE. The occupational and psychosocial impact of SARS on academic physicians in three affected hospitals. Psychosomatics. 2005;46:385-91.

64. Koh D, Lim MK, Chia SE, Ko SM, Qian F, Ng V, et al. Risk perception and impact of Severe Acute Respiratory Syndrome (SARS) on work and personal lives of healthcare workers in Singapore: what can we learn? Med Care. 2005;43:676-82.

65. Lee S, Chan LY, Chau AM, Kwok KP, Kleinman A. The experience of SARS-related stigma at Amoy Gardens. Soc Sci Med. 2005;61:2038-46.

66. Lau JT, Yang $X$, Wong $E$, Tsui $H$. Prevalence and factors associated with social avoidance of recovered SARS patients in the Hong Kong general population. Health Educ Res. 2006;21:662-73.

67. Goulia P, Mantas C, Dimitroula D, Mantis D, Hyphantis T. General hospital staff worries, perceived sufficiency of information and associated psychological distress during the $A / H 1 N 1$ influenza pandemic. BMC Infect Dis. 2010;10:322.

68. Etard JF, Sow MS, Leroy S, Touré A, Taverne B, Keita AK, et al. Multidisciplinary assessment of post-Ebola sequelae in Guinea (Postebogui): an observational cohort study. Lancet Infect Dis. 2017;17:545-52.

69. Jalloh MF, Robinson SJ, Corker J, Li W, Irwin K, Barry AM, et al. Knowledge, attitudes, and practices related to Ebola Virus Disease at the end of a national epidemic-Guinea, August 2015. MMWR Morb Mortal Wkly Rep. 2017;66:1109-65.

70. Jalloh MF, Sengeh $P$, Monasch $R$, Jalloh MB, DeLuca N, Dyson M, et al. National survey of Ebola-related knowledge, attitudes and practices before the outbreak peak in Sierra Leone: August 2014. BMJ Glob Health. 2017;2:e000285.

71. Tenkorang EY. Ebola-related stigma in Ghana: individual and community level determinants. Soc Sci Med. 2017;182:142-9.

72. Etokidem AJ, Ago BU, Mgbekem M, Etim A, Usoroh E, Isika A. Ebola virus disease: assessment of knowledge, attitude and practice of nursing students of a Nigerian University. Afr Health Sci. 2018;18:55-65.

73. Kelly JD, Weiser SD, Wilson B, Cooper JB, Glayweon M, Sneller MC, et al. Ebola virus disease-related stigma among survivors declined in Liberia over an 18month, post-outbreak period: an observational cohort study. PLoS Negl Trop Dis. 2019:13:e0007185.

74. Alzoubi H, Alnawaiseh N, Al-Mnayyis A, Abu-Lubad M, Aqel A, Al-Shagahin H. Covid-19-knowledge, attitude and practice among medical and non-medical university students in Jordan. J Pure Appl Microbiol. 2020;14:17-24.

75. James PB, Wardle J, Steel A, Adams J. An assessment of Ebola-related stigma and its association with informal healthcare utilisation among Ebola survivors in Sierra Leone: a cross-sectional study. BMC Public Health. 2020;20:182.

76. Kebede $Y$, Yitayih Y, Birhanu Z, Mekonen S, Ambelu A. Knowledge, perceptions and preventive practices towards COVID-19 early in the outbreak among Jimma 
university medical center visitors, Southwest Ethiopia. PLoS One. 2020;15: e0233744.

77. Raab M, Pfadenhauer LM, Millimouno TJ, Hoelscher M, Froeschl G. Knowledge, attitudes and practices towards viral haemorrhagic fevers amongst healthcare workers in urban and rural public healthcare facilities in the N'zerekore prefecture, Guinea: a cross-sectional study. BMC Public Health. 2020;20:296.

78. Abdel Wahed WY, Hefzy EM, Ahmed MI, Hamed NS. Assessment of knowledge, attitudes, and perception of health care workers regarding COVID-19, a crosssectional study from Egypt. J Community Health. 2020;45:1242-51.

79. Abdelhafiz AS, Mohammed Z, Ibrahim ME, Ziady HH, Alorabi M, Ayyad M, et al. Knowledge, perceptions, and attitude of Egyptians towards the novel coronavirus disease (COVID-19). J Community Health. 2020;45:881-90.

80. Abuhammad S, Alzoubi K, Khabour O. Fear of COVID-19 and stigmatization toward infected people among Jordanian people. Int J Clin Pr. 2020;75:e13899.

81. Aqeel U, Ali MD, lqbal Z, Mirza MA. Knowledge, attitudes, and practices toward coronavirus disease-19 infection among residents of Delhi NCR, India: a crosssectional survey based study. Asian J Pharm Clin Res. 2020;13:110-6.

82. Cassiani-Miranda CA, Campo-Arias A, Tirado-Otálvaro AF, Botero-Tobón LA, Upegui-Arango LD, Rodríguez-Verdugo MS, et al. Stigmatisation associated with COVID-19 in the general Colombian population. Int J Soc Psychiatry. 2020. https://doi.org/10.1177/0020764020972445.

83. Chen X, Gao H, Zou Y, Lin F. Changes in psychological wellbeing, attitude, and information-seeking behavior among people at the epicenter of the COVID-19 pandemic: a panel survey of residents in Hubei province, China. Epidemiol Infect. 2020;148:e201.

84. Elhadi $M$, Msherghi A, Elgzairi M, Alhashimi A, Bouhuwaish A, Biala $M$, et al. Psychological status of healthcare workers during the civil war and COVID-19 pandemic: a cross-sectional study. J Psychosom Res. 2020;137:110221.

85. Taylor S, Landry CA, Rachor GS, Paluszek MM, Asmundson GJG. Fear and avoidance of healthcare workers: an important, under-recognized form of stigmatization during the COVID-19 pandemic. J Anxiety Disord. 2020;75:102289.

86. Tee ML, Tee CA, Anlacan JP, Aligam KJG, Reyes PWC, Kuruchittham V, et al. Psychological impact of COVID-19 pandemic in the Philippines. J Affect Disord. 2020;277:379-91.

87. Wei L, Sha Z, Wang Y, Zhang G, Jia H, Zhou S, et al. Willingness and beliefs associated with reporting travel history to high-risk coronavirus disease 2019 epidemic regions among the Chinese public: a cross-sectional study. BMC Public Health. 2020;20:1164.

88. Badi S, Abdulraheem M, Mustafa A, Matar M, Yousef B. Knowledge, attitude, and practice of university students toward COVID-19 in Sudan: an online-based cross-sectional study. Curr Med Issues. 2021;19:70-77.

89. Greene T, Harju-Seppänen J, Adeniji M, Steel C, Grey N, Brewin CR, et al. Predictors and rates of PTSD, depression, and anxiety in UK frontline health and social care workers during COVID-19. Eur J Psychotraumatol. 2021;12:1882781.

90. Harjana NPA, Januraga PP, Indrayathi PA, Gesesew HA, Ward PR. Prevalence of depression, anxiety, and stress among repatriated Indonesian migrant workers during the COVID-19 pandemic. Front Public Health. 2021;9:630295.

91. Jassim G, Jameel M, Brennan E, Yusuf M, Hasan N, Alwatani Y. Psychological impact of COVID-19, isolation, and quarantine: a cross-sectional study. Neuropsychiatr Dis Treat. 2021;17:1413-21.

92. Kirk AHP, Chong SL, Kam KQ, Huang W, Ang LSL, Lee JH, et al. Psychosocial impact of the COVID-19 pandemic on paediatric healthcare workers. Ann Acad Med Singap. 2021;50:203-11.

93. Lam MH-B, Wing Y-K, Yu MW-M, Leung C-M, Ma RCW, Kong APS, et al. Mental morbidities and chronic fatigue in severe acute respiratory syndrome survivors: long-term follow-up. Arch Intern Med. 2009;169:2142-7.

94. Lau J, Tan DHY, Wong GJ, Lew YJ, Chua YX, Low LL, et al.The impact of COVID-19 on private and public primary care physicians: a cross-sectional study.J Infect Public Health. 2021;14:285-9.

95. Li L, Wang J, Leng A, Nicholas S, Maitland E, Liu R. Will COVID-19 vaccinations end discrimination against COVID-19 patients in China? New evidence on recovered COVID-19 patients. Vaccines. 2021;9:490.

96. Misery L, Fluhr JW, Beylot-Barry M, Jouan N, Hamann P, Consoli SG, et al. Psychological and professional impact of COVID-19 lockdown on French dermatologists: Data from a large survey. Ann Dermatol Venereol. 2021;148:101-5.

97. Moideen S, Uvais NA, Rajagopal S, Maheshwari V, Gafoor TA, Sherief SH. COVID19-related stigma among inpatients with COVID-19 infection: a cross-sectional study from India. Prim Care Companion CNS Disord. 2021;23:20br02853.

98. Poyraz B, Poyraz CA, Olgun Y, Gürel Ö, Alkan S, Özdemir YE, et al. Psychiatric morbidity and protracted symptoms after COVID-19. Psychiatry Res. 2021;295:113604.

99. Rahim BIH. Knowledge, attitudes, and practices of staff and students at Sulaiman polytechnic university towards COVID-19//raq. Indian J Forensic Med Toxicol. 2020;14:814-21.
100. Robinson E, Daly M. Explaining the rise and fall of psychological distress during the COVID-19 crisis in the United States: longitudinal evidence from the understanding America study. Br J Health Psychol. 2021;26:570-87.

101. Singh S, Chaudhary A, Satija M, Sharma P. From knowledge to practice: are we prepared to handle covid-19 pandemic? A health centre based cross-sectional study. J Clin Diagn Res. 2021;15:LC06-LC12.

102. Wang $Q$, Feng $H$, Wang $M$, Xie $Y$, Hou B, Lu X, et al. Mental health and psychological responses during the Coronavirus Disease 2019 epidemic: a comparison between Wuhan and other areas in China. Psychosom Med. 2021;83:322-7.

103. Yu N, Pan S, Yang C-C, Tsai J-Y. Exploring the role of media sources on COVID19-related discrimination experiences and concerns among Asian people in the United States: cross-sectional survey study. J Med Internet Res. 2020;22:e21684.

104. Yu Y, She R, Luo S, Xin M, Li L, Wang S, et al. Factors influencing depression and mental distress related to COVID-19 among university students in China: online cross-sectional mediation study. JMIR Ment Health. 2021;8:e22705.

105. Yufika A, Pratama R, Anwar S, Winardi W, Librianty N, Prashanti NAP, et al. Stigma against COVID-19 among health care workers in Indonesia. Disaster Med Public Health Prep. 2021. https://doi.org/10.1017/dmp.2021.93.

106. Lau JT, Yang X, Tsui H, Kim JH. Monitoring community responses to the SARS epidemic in Hong Kong: from day 10 to day 62. J Epidemiol Community Health. 2003;57:864-70.

107. Adongo PB, Tabong PT, Asampong E, Ansong J, Robalo M, Adanu RM. Beyond knowledge and awareness: addressing misconceptions in Ghana's preparation towards an outbreak of Ebola virus disease. PLoS One. 2016;11:e0149627.

108. The Lancet. COVID-19. protecting health-care workers. Lancet. 2020;395:922.

109. Pappa S, Ntella V, Giannakas T, Giannakoulis VG, Papoutsi E, Katsaounou P. Prevalence of depression, anxiety, and insomnia among healthcare workers during the COVID-19 pandemic: a systematic review and meta-analysis. Brain Behav Immun. 2020;88:901-7.

110. Que J, Shi L, Deng J, Liu J, Zhang L, Wu S, et al. Psychological impact of the COVID-19 pandemic on healthcare workers: a cross-sectional study in China. Gen Psychiatr. 2020;33:e100259.

111. Naeem SB, Bhatti R. The Covid-19 'infodemic': a new front for information professionals. Health Info Libr J. 2020;37:233-9.

112. Que J, Yuan K, Gong Y, Meng S, Bao Y, Lu L. Raising awareness of suicide prevention during the COVID-19 pandemic. Neuropsychopharmacol Rep. 2020;40:392-5.

113. Shi L, Que J, Lu Z, Gong Y, Liu L, Wang Y, et al. Prevalence and correlates of suicidal ideation among the general population in China during the COVID-19 pandemic. Eur Psychiatr. 2021;64:e18.

114. Malecki K, Keating JA, Safdar N. Crisis communication and public perception of COVID-19 risk in the era of social media. Clin Infect Dis. 2020;72:697-702.

115. Gollust SE, Nagler RH, Fowler EF. The emergence of COVID-19 in the U.S.: a public health and political communication crisis. J Health Polit Policy Law. 2020;45:967-81.

116. Nyakarahuka L, Skjerve E, Nabadda D, Sitali DC, Mumba C, Mwiine FN, et al. Knowledge and attitude towards Ebola and Marburg virus diseases in Uganda using quantitative and participatory epidemiology techniques. PLoS Negl Trop Dis. 2017;11:e0005907.

117. Miller CT, Kaiser CR. A theoretical perspective on coping with stigma. J Soc Issues. 2001;57:73-92.

118. Des Jarlais DC, Galea S, Tracy M, Tross S, Vlahov D. Stigmatization of newly emerging infectious diseases: AIDS and SARS. Am J Public Health. 2006;96:561-7.

119. Crawford AM. Stigma associated with AIDS: a meta-analysis. J Appl Soc Psychol. 1996;26:398-416.

120. Mak WW, Mo PK, Cheung RY, Woo J, Cheung FM, Lee D. Comparative stigma of HIV/AIDS, SARS, and tuberculosis in Hong Kong. Soc Sci Med. 2006;63:1912-22.

121. Turan JM, Elafros MA, Logie $C H$, Banik S, Turan B, Crockett KB, et al. Challenges and opportunities in examining and addressing intersectional stigma and health. BMC Med. 2019;17:7.

122. World Health Organization. A guide to preventing and addressing social stigma associated with COVID-19. 2020. https://www.who.int/publications/m/item/aguide-to-preventing-and-addressing-social-stigma-associatedwith-covid-19? gclid=EAlalQobChMljaPxkeCL17wIVzKiWCh13mMgS17EAAYASAAEgL13o D BwE. Accessed 27 May 2021.

123. Prevention CfDCa. Reducing stigma. 2020. https://www.cdc.gov/coronavirus/ 2019-ncov/daily-life-coping/reducing-stigma.html. Accessed 27 May 2021.

124. Sylvia Chou WY, Gaysynsky A. Racism and xenophobia in a pandemic: interactions of online and offline worlds. Am J Public Health. 2021;111:773-5.

125. Clissold E, Nylander D, Watson C, Ventriglio A. Pandemics and prejudice. Int J Soc Psychiatry. 2020;66:421-3.

126. Graham N, Lindesay J, Katona C, Bertolote JM, Camus V, Copeland JR, et al. Reducing stigma and discrimination against older people with mental disorders: a technical consensus statement. Int J Geriatr Psychiatry. 2003;18:670-8. 
127. Yuan Y, Zhao YJ, Zhang QE, Zhang L, Cheung T, Jackson T, et al. COVID-19related stigma and its sociodemographic correlates: a comparative study. Glob Health. 2021;17:54

\section{AUTHOR CONTRIBUTIONS}

$\mathrm{LL}, \mathrm{BYP}, \mathrm{SL}$, and $\mathrm{YK}$ proposed the topic and main idea. YK, HXL, and YW contributed equally to this article. $H X L$ and $Z Y X$ were responsible for the literature search and study selection. HXL, GYM, SSZ, HYT, ZY, WYJ, YZ, TSS, ZYB, FT, ZYJ, and YW were responsible for the data extraction and quality assessment. $\mathrm{HXL}$ and $Y K$ wrote the initial draft. YK, HXL, SSZ, YW, ZYJ, MSQ, SYK, LX, ZTM, RMS, WSYSW, RN, SL, BYP, and $\mathrm{LL}$ commented on and revised the paper. $\mathrm{LL}, \mathrm{BYP}$, and $\mathrm{SL}$ made the final version. All authors contributed to the final draft of the paper.

\section{FUNDING}

This work was supported by the National Key Research and Development Program of China [No. 2021YFC0863700, 2019YFA0706200], the National Natural Science Foundation of China [no. 81761128036, 81821092, 81901345, and 82001404]
Stigmatization of Suddenly Emerging Infectious Diseases and its Intervention Mechanism, the National Social Science Fund of China [no. 20CSH028].

\section{COMPETING INTERESTS}

The authors declare no competing interests.

\section{ADDITIONAL INFORMATION}

Supplementary information The online version contains supplementary material available at https://doi.org/10.1038/s41380-021-01295-8.

Correspondence and requests for materials should be addressed to Le Shi, Yan-Ping Bao or Lin Lu.

Reprints and permission information is available at http://www.nature.com/ reprints

Publisher's note Springer Nature remains neutral with regard to jurisdictional claims in published maps and institutional affiliations. 